
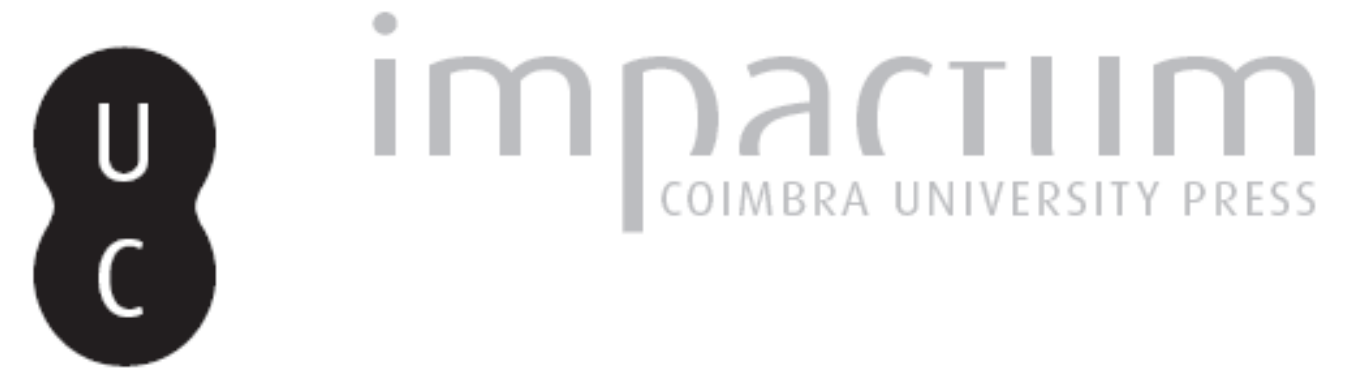

\title{
Polimorfismos genéticos de ESD, GL01, GPT e PGM1 em São Tomé e Príncipe
}

\begin{abstract}
Autor(es): $\quad$ Trovoada, Maria de Jesus; Manco, Licínio; Amorim, António; Abade, Augusto; Prata, Maria João; Santos, Maria Teresa
\end{abstract}

Publicado por: CIAS - Centro de Investigação em Antropologia e Saúde

URL persistente:

URI:http://hdl.handle.net/10316.2/41277

DOI:

DOI:http://dx.doi.org/10.14195/2182-7982_18_7

Accessed : $\quad$ 26-Apr-2023 04:12:18

A navegação consulta e descarregamento dos títulos inseridos nas Bibliotecas Digitais UC Digitalis, UC Pombalina e UC Impactum, pressupõem a aceitação plena e sem reservas dos Termos e Condições de Uso destas Bibliotecas Digitais, disponíveis em https://digitalis.uc.pt/pt-pt/termos.

Conforme exposto nos referidos Termos e Condições de Uso, o descarregamento de títulos de acesso restrito requer uma licença válida de autorização devendo o utilizador aceder ao(s) documento(s) a partir de um endereço de IP da instituição detentora da supramencionada licença.

Ao utilizador é apenas permitido o descarregamento para uso pessoal, pelo que o emprego do(s) título(s) descarregado(s) para outro fim, designadamente comercial, carece de autorização do respetivo autor ou editor da obra.

Na medida em que todas as obras da UC Digitalis se encontram protegidas pelo Código do Direito de Autor e Direitos Conexos e demais legislação aplicável, toda a cópia, parcial ou total, deste documento, nos casos em que é legalmente admitida, deverá conter ou fazer-se acompanhar por este aviso.

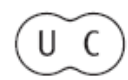


Antropologia Portuguesa

Volume $18 \cdot 2001$

Departamento de Antropologia | Universidade de Coimbra 


\title{
Polimorfismos genéticos de ESD, GLO1, GPT e PGM1 em São Tomé e Príncipe
}

\author{
Maria de Jesus Trovoada', Licínio Manco', António Amorim ${ }^{2,3}$, Augusto \\ Abade', Maria Joăo Prata', ${ }^{2,3}$, Maria Teresa Santos ${ }^{2}$ \\ 'Departamento de Antropologia \\ Universidade de Coimbra \\ 3000-056 Coimbra, Portugal \\ 'Faculdade de Cièncias \\ Universidade do Porto, Portugal \\ 'Instituto de Patologia e Imunologia Molecular \\ Universidade do Porto, Portugal \\ mjesus@i.uc.pt
}

Resumo Neste trabalho procedeu-se ao estudo das distribuiçōes fenotipicas da esterase D (ESD), da Glioxalase 1 (GLO1), da transaminase glutámico pirúvica (GPT), e da fosfoglucomutase I (PGMI) utilizando glóbulos vermelhos de indivíduos nāo aparentados naturais e residentes em São Tomé e Príncipe, com vista à caracterização genética dessa população. A fenotipagem foi realizada por electroforese em gel de amido. As frequências alélicas estimadas foram as seguintes: $\mathrm{ESD}^{*} 1=0.929, \mathrm{ESD}^{*} 2=0.071(\mathrm{~N}=145) ; \mathrm{GLOl}^{*} 1=0.347, \mathrm{GLO} 1 * 2=0.653(\mathrm{~N}=154) ;$ $\mathrm{GPT}^{*} 1=0.840, \mathrm{GPT}^{*} 2=0.160(\mathrm{~N}=150) ; \mathrm{PGM} 1 * 1=0.809, \mathrm{PGM} 1 * 2=0.191(\mathrm{~N}=257)$.

Palavras-chave Genética populacional; ESD; GLOI; GPT; PGM1; São Tomé e Principe.

Abstract The distribution of phenotypes of the red cell esterase D (ESD), glyoxalase 1 (GLO1), glutamate pyruvate transaminase (GPT) and phosphoglucomutase 1 (PGM1) were analysed by starch gel electrophoresis in unrelated nativeborn residents in São Tomé and Principe, for the purpose of genetic characterization of this population. The allele frequencies found were:

$\mathrm{ESD}^{*}=0.929, \mathrm{ESD}^{*} 2=0.07 \mathrm{I}(\mathrm{N}=145) ; \mathrm{GLOI}^{*} \mathrm{I}=0.347, \mathrm{GLO}^{*} 2=0.653(\mathrm{~N}=154)$; $\mathrm{GPT}^{*} 1=0.840, \mathrm{GPT}^{*} 2=0.160(\mathrm{~N}=150) ; \mathrm{PGM} 1 * 1=0.809, \mathrm{PGM}^{*}{ }^{*}=0.191(\mathrm{~N}=257)$.

Key words Genetic polymorphisms; ESD; GLO1; GPT; PGM1; São Tomé and Príncipe. 


\section{Introdução}

São Tomé e Principe é um arquipélago situado no Golfo da Guiné a cerca de 150 milhas da costa africana e, actualmente, possui aproximadamente 159900 habitantes. Supõe-se estar desabitado na altura da descoberta, em 1471. Para o povoamento inicial, a principal contribuição demográfica foi dada por escravos trazidos de países da costa ocidental africana (Tenreiro, 1961; Almeida, 1966; Ambrósio, 1984).

Neste trabalho, os polimorfismos genéticos de esterase D (ESD: EC.3.1.1.1), de glioxalase 1 (GLO1: EC.4.4.1.5), de transaminase glutámico pirúvica (GPT: EC:2.6.1.2), e de fosfoglucomutase 1 (PGM1: EC.2.7.5.1) foram estudados em indivíduos de São Tomé e Príncipe, tendo em vista a caracterização genética dessa população. As frequências génicas estimadas foram comparadas com as previamente descritas para outras populações.

\section{Material e Métodos}

Colheram-se amostras de sangue, por punção venosa, de indivíduos não aparentados naturais e residentes em São Tomé e Príncipe. Os glóbulos vermelhos depois de separados foram armazenados num meio de glicerol a $-20^{\prime \prime} \mathrm{C}$. A separação dos eritrócitos foi feita pelo método de Siebert, Ritter e Kompf (1979).

As fenotipagens foram realizadas por electroforese horizontal em gel de amido, seguida de detecção específica para cada marcador, segundo Amorim (1983). As frequências génicas foran calculadas pelo método de contagem directa. As distâncias genéticas de Reynolds foram utilizadas para construir uma árvore filogenética com o pacote informático PHYLIP 3.5, (Felsenstein, 1993). Recorreu-se ao programa Treeview vs 1.5 (Page, 1996) para a representação gráfica da árvore.

\section{Resultados e Discussão}

Relativamente aos quatro loci analisados, apenas foram encontrados os fenótipos resultantes da combinação de produtos génicos mais comuns desses marcadores (Harris e Hopkinson, 1976). 
$\mathrm{Na}$ tabela $\mathrm{I}$ apresentam-se as distribuições fenotípicas observadas em São Tomé e Principe, bem como as estimativas de frequências génicas. $\mathrm{Na}$ amostra analisada não se detectou discordância entre a distribuição fenotípica observada e a esperada segundo o formalismo de Hardy-Weinberg.

Tabela 1. Distribuiçāo fenotipica e frequências génicas de ESD, GLO1, GPT e PGM1 em São Tomé e Principe.

\begin{tabular}{|c|c|c|c|c|}
\hline Locus & Fenátipos & Observados & Esperados & Frequència Génica \\
\hline \multirow[t]{5}{*}{$\overline{E S D}$} & & & & \\
\hline & 1 & 127 & 121.71 & $E D^{*} 1=0.929 \pm 0.015$ \\
\hline & 2-1 & 16 & 18.58 & $E S D^{*} 2=0.071 \pm 0.015$ \\
\hline & 2 & 2 & 0.71 & \\
\hline & Outros & 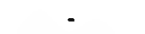 & 4.00 & \\
\hline Total & & 145 & 145.00 & $\chi^{2}=2.72 ; 1$ g.l.; $0.05<P<0.10$ \\
\hline \multicolumn{5}{|l|}{ GLOI } \\
\hline & 1 & 22 & 18.57 & GLO1* $1=0.347 \pm 0.073$ \\
\hline & $2-1$ & 63 & 69.83 & $\mathrm{GLO} 1 * 2=0.653 \pm 0.073$ \\
\hline & 2 & 69 & 65.59 & \\
\hline Total & & 154 & 154.00 & $\chi Z=1.47 ; 1$ g.l. $00.20<P<0.30$ \\
\hline \multicolumn{5}{|l|}{ GPT } \\
\hline & 1 & 108 & 105.84 & $\mathrm{GPT}^{*} 1=0.840 \pm 0.021$ \\
\hline & $2-1$ & 36 & 40.32 & $G P T * 2=0.160 \pm 0.021$ \\
\hline & 2 & 6 & 3.84 & \\
\hline & Outros & & & \\
\hline Total & & 150 & 150.00 & $\chi^{2}=1.72 ; 1$ g.l.; $0.20<P<0.30$ \\
\hline PGMI & 1 & 171 & 168.34 & $P G M 1 * 1=0.809 \pm 0.003$ \\
\hline & 2-1 & 74 & 79.32 & PGM1*2=0.191 \pm 0.003 \\
\hline & $\begin{array}{c}2 \\
\text { Outros }\end{array}$ & 12 & 9.34 & \\
\hline Total & & 257 & 257.00 & $x^{2}=1.56 ; 1$ q.1.; $0.20<P<0.30$ \\
\hline
\end{tabular}

Ao contrário dos valores reportados para a população de Cabo Verde, particularmente quanto a ESD e GLO1 que reflectem a forte influência europeia a que o arquipélago esteve sujeito, as frequências génicas estimadas para a população de São Tomé e Príncipe encaixam-se no intervalo de variação observado em populações africanas (tabelas $2,3,4$ e 5 ).

$\mathrm{O}$ agrupamento obtido por Neighbour Joining apresentado na figura 1 , evidencia um consenso elevado ( 920 em 1000 bootstraps) a separar as populações africanas e as europeias e, em consonância com os dados obtidos, a inserção da população de São Tomé e Príncipe no grupo africano. 
Tabela 2. Frequências génicas de ESD em populações africanas e europeias.

\begin{tabular}{|c|c|c|c|c|c|}
\hline População & $\mathrm{N}$ & ESD' & $\mathrm{ESD}^{2}$ & $\mathrm{ESD}^{5}$ & Referências \\
\hline Africa do Sul (Negros) & 900 & 0.970 & 0.030 & & May et al. $(1990)$ \\
\hline Alemanha & 1129 & 0.880 & 0.108 & 0.012 & Schmidt e Scheil (1096) \\
\hline Benin (Masteri) & 285 & 0.951 & 0.049 & & Biondi et al. (1996) \\
\hline Camarōes & 283 & 0.9 & 0.026 & & Goedde ef al. (1979) \\
\hline Cabo Verde & 267 & 0.824 & 0.176 & & Parra et at $(1995)$ \\
\hline Congo (Beti) & 95 & 0.921 & 0.079 & & Destro-Bisol ef al. (1986) \\
\hline Guiné Equatorial & 118 & 0.831 & 0.119 & & Morilla et ad $\{1988\}$ \\
\hline Portugal (Centro) & 70 & 0.860 & 0.140 & & Carvalho ot al. (1991) \\
\hline República Centro Africana & 50 & 0.910 & 0.090 & & Destro-Bisol et al. (1986) \\
\hline Ruanda & 245 & 0.7 & 0.247 & & Le Gall et al. (1982) \\
\hline São Tomé e Principe & 1.45 & 0.929 & 0.071 & & Este trabalho \\
\hline
\end{tabular}

Tabela 3. Frequências génicas de GLO1 em populaçōes africanas e europeias.

\begin{tabular}{|c|c|c|c|c|}
\hline População & $\mathrm{N}$ & GLOI' & $\mathrm{GLOI}^{2}$ & Referências \\
\hline Árica do Sul (Negros) & 672 & 0.256 & 0.744 & May et al. ([ 990) \\
\hline Alemanha & 1076 & 0.440 & 0.560 & Schmidt e Scheil (1996) \\
\hline Benin (Materi) & 285 & 0.312 & 0.688 & Biondi of al (1996) \\
\hline Camarōes & 280 & 0.337 & 0.663 & Goedde ef al. (1979) \\
\hline Cabo Verde & 268 & 0.403 & 0.597 & Parra ct al. (1995) \\
\hline Guiné Equalorial & 118 & 0.297 & 0.703 & Morilla et al. (1988) \\
\hline Portugal (Norte) & 987 & 0.436 & 0.564 & Amorim (1983) \\
\hline República Centro Africana & 92 & 0.272 & 0.728 & Spedini et al. (1983) \\
\hline São Tomé \& Principe & 154 & 0.347 & 0.653 & Este trabalho \\
\hline
\end{tabular}

Tabela 4. Frequências génicas de GPT em populações africanas e europeias.

\begin{tabular}{|c|c|c|c|c|c|c|}
\hline População & $\mathrm{N}$ & $\mathrm{GPT}^{1}$ & $\mathrm{GPT}^{2}$ & $\mathrm{GPT}^{\mathrm{NA}}$ & $\mathrm{GPT}^{3}$ & Referências \\
\hline Álrica do Sul (Negros) & 973 & 0.889 & 0.111 & & & Hitzeroth et al. (1981) \\
\hline Alemanha & 1113 & 0.516 & 0.484 & & & Schmidut a Scheil (1996) \\
\hline Camarōes & 279 & 0.869 & 0.131 & & & Goedde el al (1979) \\
\hline Congo (Negros) & 85 & 0.841 & 0.159 & & & Chen er al (1972) \\
\hline Gämbia (Keneba) & 652 & 0.809 & 0.191 & & & Weich (1975) \\
\hline Guiné Equatorial & 32 & 0.844 & 0.156 & & & Morilla ot al. (1988) \\
\hline Moçambique & 94 & 0.872 & 0.128 & & & Chen ef al (1972) \\
\hline Portugal & 796 & 0.483 & 0.507 & 0.009 & 0.001 & Amorim (1983) \\
\hline Quinia (Negros) & 63 & 0.857 & 0.143 & & & Chen es al. (1972) \\
\hline Ruanda & 245 & 0.869 & 0.131 & & & Le Gall et al. (1982) \\
\hline Sāo Tomé e Principe & 150 & 0.840 & 0.160 & & & Este traballio \\
\hline Zâmbia & 76 & 0.921 & 0.079 & & & Welch (1972) \\
\hline
\end{tabular}


Tabela 5. Frequências génicas de PGM1 em populaçōes africanas e europeias.

\begin{tabular}{|c|c|c|c|c|c|c|}
\hline População & $\mathrm{N}$ & PGM $^{1}$ & $\mathrm{PGM}^{2}$ & $\mathrm{PGM}^{3}$ & $\mathrm{PGM}^{4}$ & Referências \\
\hline África do Sul (Negros) & 1170 & 0.819 & 0.178 & & & May et al. $(1990)$ \\
\hline Alemanba & 1090 & 0.625 & 0.185 & 0.131 & 0.059 & Schmidt e Scheil (1996) \\
\hline Benin (Tofinu) & 103 & 0.820 & 0.180 & & & Spedini et al. (1980) \\
\hline Camarūes & 284 & 0.745 & 0.255 & & & Goedde et al. (1979) \\
\hline Guiné Equatoria! & 116 & 0.767 & 0.233 & & & Morilla et al. (1988) \\
\hline Nigéria (Yorubas) & 153 & 0.761 & 0.239 & & & Hopkinson e Harris ( 1966 ) \\
\hline Moçambique & 318 & 0.781 & 0.219 & & & Giblett (1969) \\
\hline Pontugal (centro) & 611 & 0.781 & 0.219 & & & Amorim (1983) \\
\hline República Centro Africana & 133 & 0.925 & 0.075 & & & Spedini et al. $(1980)$ \\
\hline São Tomé e Principe & 257 & 0.809 & 0.191 & & & Este traballıo \\
\hline
\end{tabular}

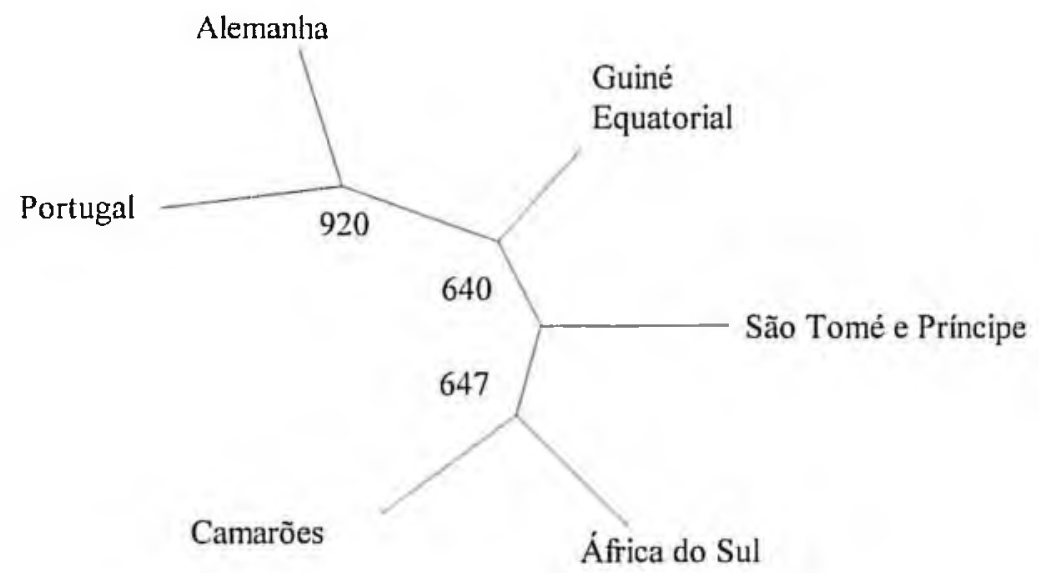

Figura 1. Agrupamento hierárquico obtido por Neigbour Joining com base em ESD, GLO1, GPT e PGM1. Os números indicam os valores de bootstrap.

\section{Conclusões}

Em nenhum dos marcadores estudados foram registadas diferenças estatisticamente significativas entre as distribuições fenotípicas observadas e as esperadas, assumindo, portanto, o equilíbrio de Hardy-Weinberg. 
As estimativas das frequências génicas para ESD, GLO1, GPT e PGM1 enquadram-se na gama de variação normalmente observada para populações de regiões sub-sarianas, e não foi possível obter indicação quanto à contribuição genética europeia na actual população de São Tomé e Príncipe. A análise baseada em frequências alélicas do tipo de marcadores estudados, tem-se afigurado pouco informativa para evidenciar pequenas misturas populacionais. Porém, unn estudo mais recente da população Sãotomense referente a polimorfismos do cromossoma $Y$ (Trovoada et al., 2001) revelou que traços de alguma miscegenação, ocorrida durante o processo de colonização do arquipélago, ainda permanecem actualmente na população.

A extensão da caracterização genética de São Tomé e Príncipe a diferentes tipos de marcadores genéticos afigura-se, assim, a via mais adequada para avaliar o impacto do fluxo genético ocorrido ao longo da história do arquipélago.

\section{Agradecimentos}

Ao Ministério da Saúde de São Tomé e Príncipe pela facilidade na colheita de amostras. Trabalho subsidiado pelo projecto STRIDE/JNICT (STRDA/CEN/532/92).

\section{Bibliografia}

Almeida, A. 1966. Das etmonimias da Guiné Portuguesa, do arquipélago de Cabo Verde e das ilhas de São-Tomé e Principe. Lisboa, Instituto Superior de Ciências Sociais e Política Ultramarina.

Ambrósio, A. 1984. Subsidios para a História de São-Tomé e Principe. Lisboa, Livros do horizonte.

Amorim, A. 1983. Contribuição para o conhecimento da genésica humana. Estudo de genética bioquímica, formal e populacional e de ligação factorial. Dissertação de Doutoramento em Biologia, Faculdade de Ciências, Universidade do Porto.

Biondi, G.; Rickards, O.; Martinez-Labarga, C.; Taraborelli, T.; Ciminelli, B.; Gruppioni, G. 1996. Biodemography and genetics of the Berba of Benin. American Joumal of Physical Anthropologn, 99 (4): 519-535. 
Carvalho, M.; Manco, L.; Amorim, A.; Rocha, J.; Santos, M. T. 1991. Fosfatase ácida, cinase adenílica, aminolevulinato desidratase e esterase D: Genética populacional na região centro de Portugal. Antropologia Portuguesa, 92 (9/10): 69-75.

Chen, S.-H.; Giblett, E. R.; Anderson, J. E.; Fossum, B. L. G. 1972. Genetics of glutamic-pyruvic transaminase: its inleritance, common and rare variants, population distribution and differences in catalytic activity. Annals of Human Genetic, 35: 401-409.

Destro-Bisol, G.; Menchicchi, F.; Ranalletta, D.; Spedini, G. 1986. EsD in Negro and Caucasian Populations: Is the EsD5 a "Caucasian allele"? Human Heredity, 36: 154-157.

Felsenstein, J. 1993. PHYLIP - Phylogeny inference package (version 3.5c). Distributed by the author. Seatle, Department of Genetics. University of Washington.

Giblett, E. R. 1969. Genetic markers in human blood. Oxford, Blackwell Scientific Publications.

Goedde, H. W.; Benkmann, H-G.; Agarwal, D. P.; Bienzle, U.; Guggenmoos, R.; Rosenkaimer, F.; Hoppe, H.-H.; Brinkmann, B. 1979. Genetic studies in Cameroon: red cell enzyme and serum protein polymorphisms. Zeitschrift fir Morphologie und Anthropologie, 70 (1): 33-40.

Harris, H.; Hopkinson, D. A. 1976. Handbook of enzymes electrophoresis in Inman Genetics. Amsterdan, North-Holland Publishing Company.

Hitzeroth, H. W.; Bender, K.; Frank, R. 1981. South African negroes: isoenzyme polymorphisms (GPT, PGM1, PGM2, AcP, AK, and ADA) and tentative genetic distances. Anthropogischer Anzeiger; 1: 20-35.

Hopkinson, D. A.; Harris, H. 1966. Rare phosphoglucomutase phenotypes. Annals of Human Genetic, 30: 167-178.

Le Gall, J. Y.; Le Gall, M.; Godin, Y.; Serre, J. L. 1982. A study of genetic markers of the blood in four Central African population groups. Human Heredity, 32: 418-427.

May, R. M.; Schlaphoff, T.; Du Toit, E. D. 1990. Red cell enzyme and serum protein polymorphism in the Western Cape region of South Africa. Gene Geography, 4: 113-124.

Morilla, J. M.; Afonso, J. M.; Hernandez, M.; Pestano, J. J.; Larruga, J. M. 1988. Human enzyme polymorphism in the Canary Islands. II. African influence. Human Heredity, 38: 101-105.

Page, R. D. M. 1996. TREEVIEW: an application to display phylogenetic trees 
on personal computers. Computer Applications in the Biosciences, 12: 357358.

Parra, E. J.; Ribeiro, J. C. Teixeira; Riveiro, A.; Vide, M. C.; Llano, C.; Caeiro, J. L. B. 1995. Red cell enzymes and plasma protein polymorphisms in the population of Cabo Verde (West Africa). American Joumal of Human Biology, 7: 707-709.

Schmidt, H. D.; Scheil, H. D. 1996. Hemogenetic studies in southern Germany. Gene Geography, 10: 191-200.

Siebert, G.; Ritter, H.; Kompf, J. 1979. Mitochondrial malic enzyme in human leukocytes formal genetics and population genetics. Human Genetic, 51: 319-322.

Spedini, G.; Fuciarelli, M.; Rickards, O. 1980. Blood polymorphism frequencies in the Tofinu, the "Water Men" of Southern Benin. Anthropogischer Anzeiger, 38 (2): 121-130.

Spedini, G.; Walter, H.; Capucci, E.; Fuciarelli, M.; Rickards, O.; Aebischer, M. L.; Crosti, N. 1983. An anthropobiological study in Basse Kotto (Central Africa). I. Erythrocyte and serum-genetic markers: an analysis of the genetic differentiation. American Joumal of Physical Anthropology, 60: 39-47.

Tenreiro, F. 1961. A ilha de São-Tomé. Lisboa, Memórias da Junta de Investigações do Ultramar.

Trovoada, M. J.; Alves, C.; Gusmão, L.; Abade, A; Amorim, A; Prata, M. J. 2001. Evidence for population sub-structuring in São Tomé e Principe as inferred from Y-chromosome STR analysis. Amals of Human Genetic, 65: 271-283.

Welch, S. G. 1972. Quantitative differences between the human red cell glutamate-pyruvate transaminase phenotypes. Human Heredity, 22: 190-197.

Welch, S. G.; Lee, J.; McGregor, I. A.; William S. K.1975. Red cell glutamatepyruvate transaminase gene frequencies in Gambia, West Africa. Human Heredity, 25: 414-417. 